\title{
ANDREAS VASSILIEVITCH MARTYNOV
}

Dr. A. V. Martynov, the distinguished Russian entomologist, died from cancer on the twenty-ninth of last January. Born at Riazan, Russia, August 9, 1879, he graduated from Moscow University in 1902 and continued there with his graduate studies. In 1908 he was appointed to the faculty of the University of Warsaw, and in 1915 moved with the University to Rostoff. Six years later he was placed at the head of the department of Neuroptera and Trichoptera at the Zoological Museum of the Academy of Sciences, in Leningrad. During this period he became interested in fossil insects and in 1936 was appointed Senior Specialist in the Department of Insecta, at the Palaeontological Institute of the Academy, in Moscow, a position which he held up to the time of his death.

Although Dr. Martynov was primarily an entomologist, he was also interested in Crustacea (Gammaridae), on which he published fifteen taxonomic papers. In addition to compiling four text-books on insects, Dr. Martynov's entomological researches were concerned with the taxonomy of the Trichoptera, general morphology, and paleoentomology. His publications on Trichoptera were almost exclusively confined to the Asiatic fauna, and he greatly extended our knowledge of the caddis-flies of that continent. His Trichopterous papers, totaling twenty-five, include approximately 1500 pages.

The studies on insect morphology dealt mainly with the wings and their venation. Of the numerous papers which he published on these structures, two are especially important -Uber zwei Grundtypen der Flügel bei den Insekten und ihre Evolution (1925) and The Interpretation of the Wing Venation and Tracheation of the Odonata and Agnatha $(1924)^{1}$. The conclusions which he independently reached

\footnotetext{
${ }^{1}$ Because of the great importance of this paper, which was printed in Russian, an English translation of it was published by the writer in Psyche, vol. 37, pp. 245-280.
} 


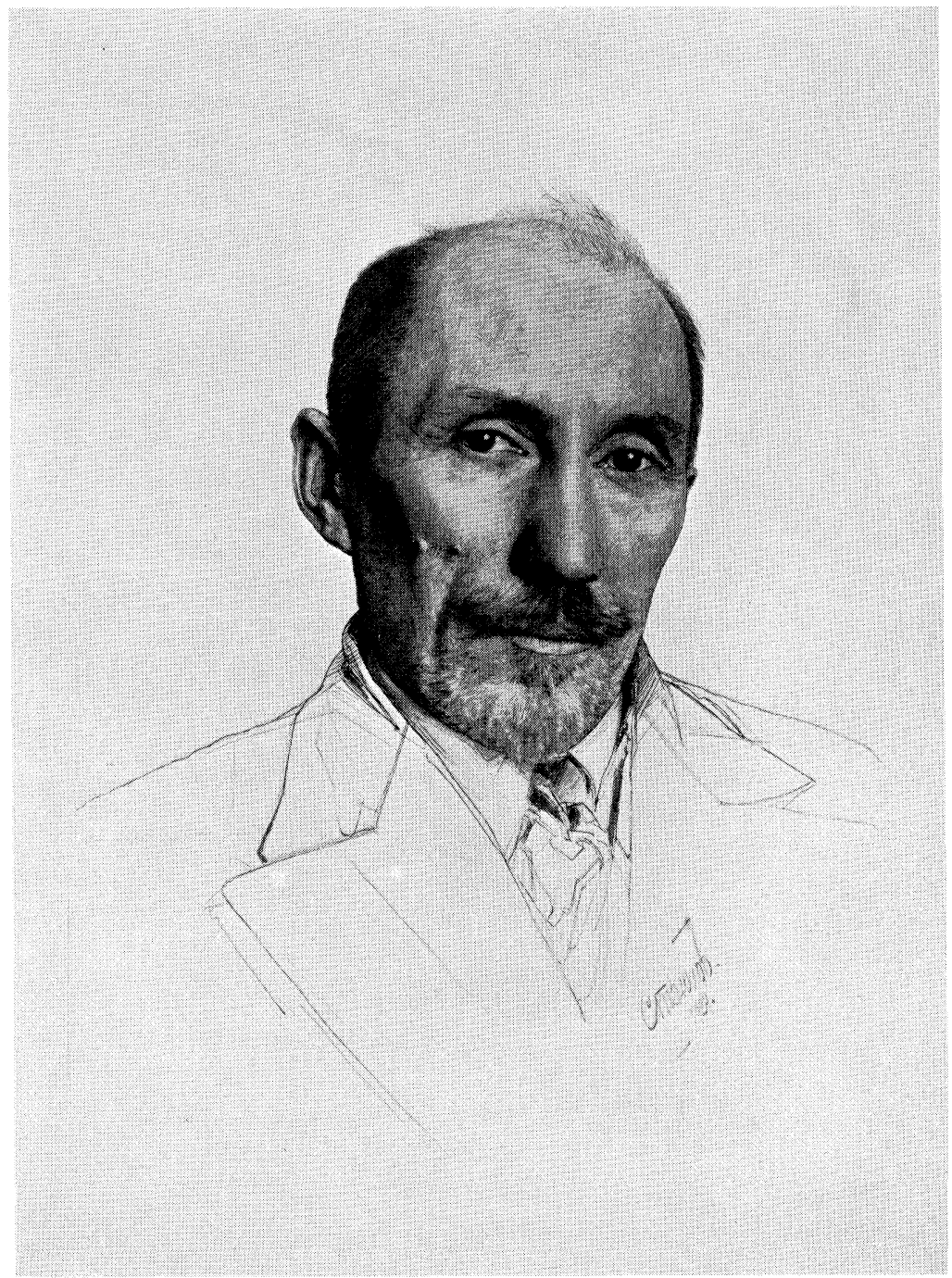

ANDREas VASSILIEVITCH MaRtynov 
in the latter paper paralleled those just previously arrived at by Lameere (1922).

It was by the researches on fossil insects, however, that Dr. Martynov made his greatest contributions to entomology. The forty papers which he published on paleoentomology contain very nearly a thousand pages. His early work on fossil insects (1925-1927) dealt with a very remarkable series of Jurassic fossils from Turkestan. In 1928, however, before he had completed his studies on these, he became interested in Permian insects and devoted most of the next ten years to them. When he began these investigations only thirteen species were known from the Permian of Russia; at the present time, almost entirely as a result of Dr. Martynov's studies and field work, the number of such species has exceeded three hundred. Their significance is apparent when we consider that they are almost the only Permian insects known, apart from those described from Kansas and Australia. The Russian Permian fauna thus fills in what would otherwise be a very disconcerting gap in our record of the Permian insects.

Although I have had a regular correspondence with Dr. Martynov for the past twelve years, since he started work on fossil insects, I did not have the opportunity to meet him, and I am consequently unable to add to this account any intimately personal details of his life. Mrs. Martynov kindly sent me the accompanying picture, which was made in 1929, while Dr. Martynov was at the Zoological Museum in Leningrad.

F. M. Carpenter. 

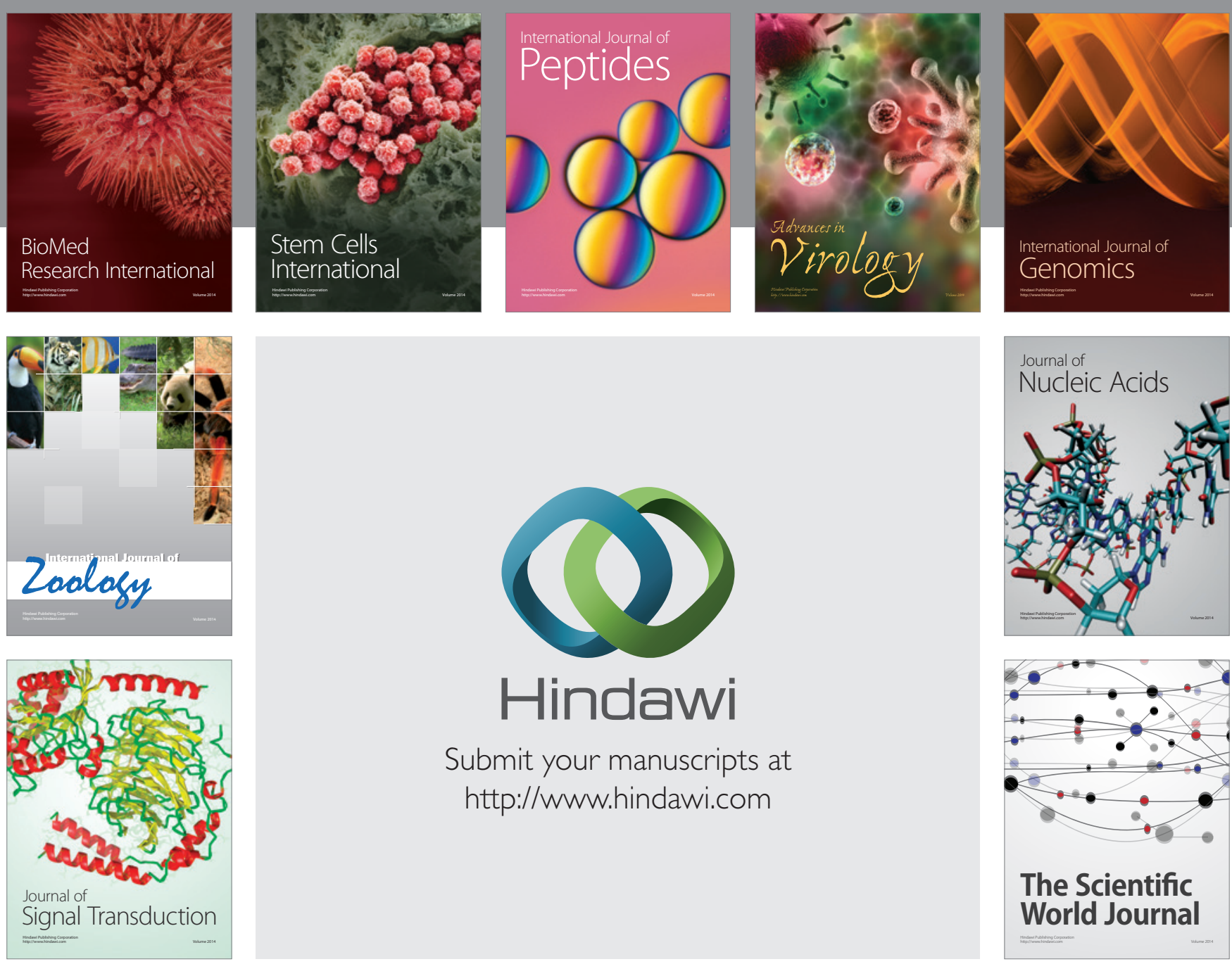

Submit your manuscripts at

http://www.hindawi.com
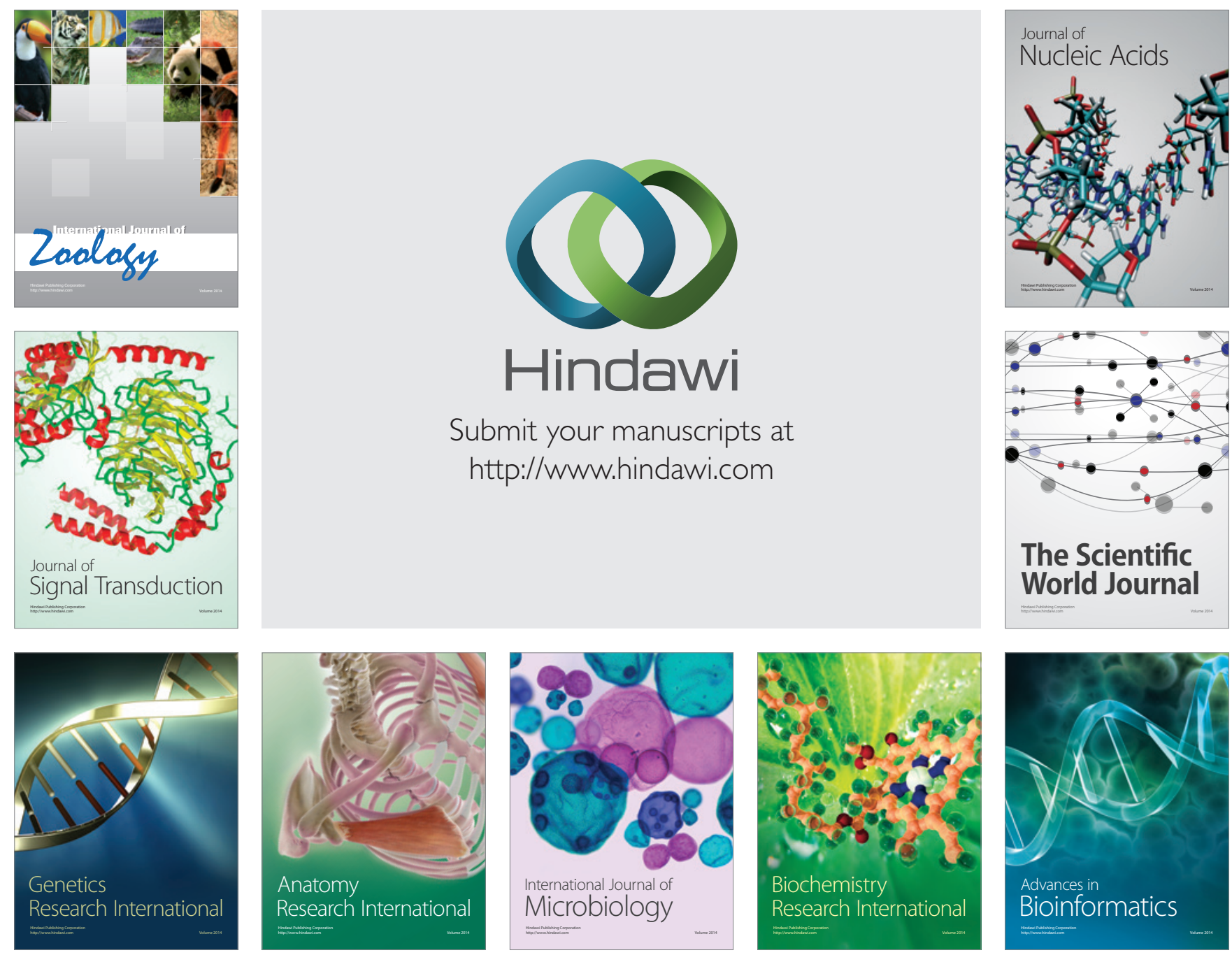

The Scientific World Journal
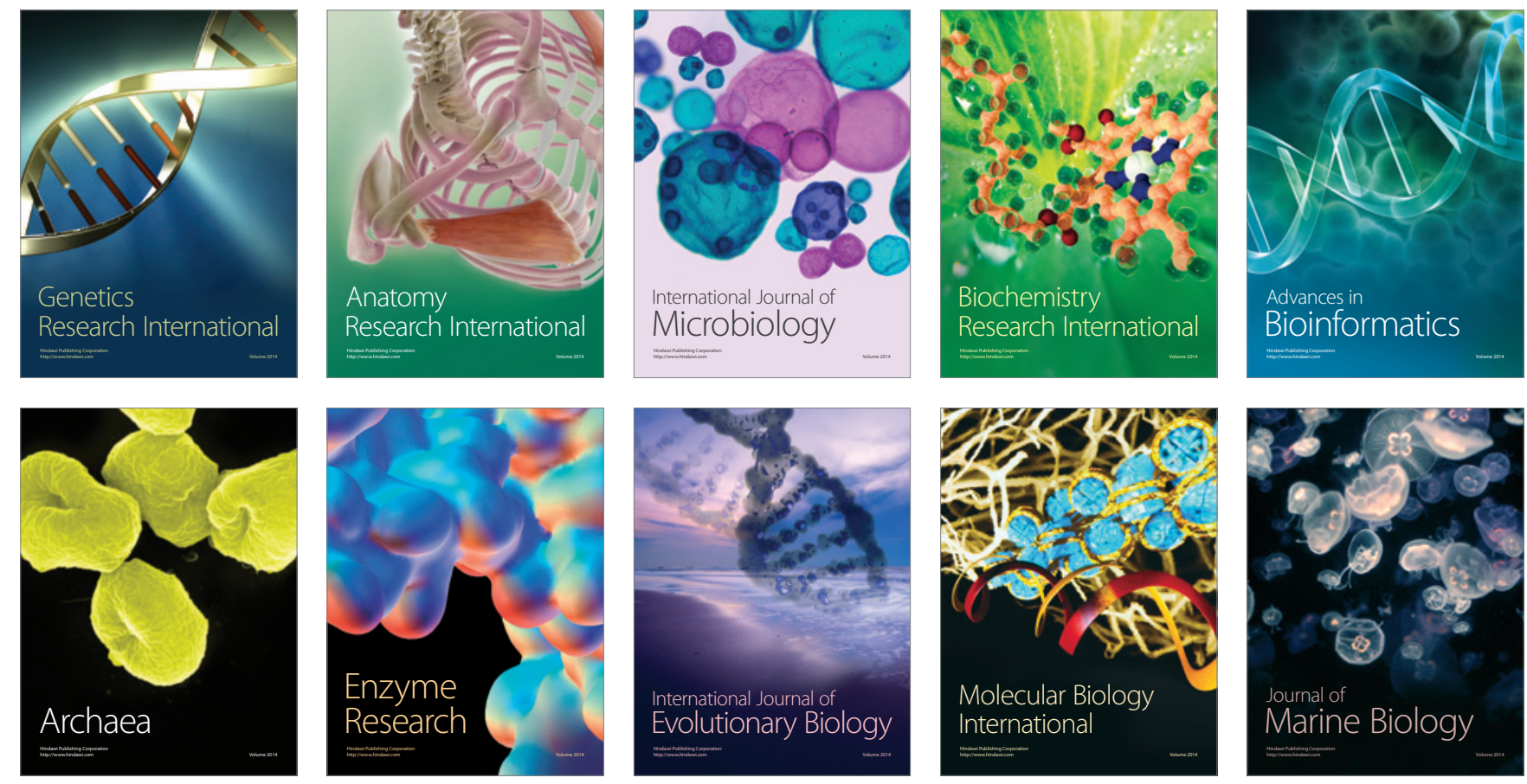